\title{
THE DEGRADATION OF HUMIC SUBSTANCE USING CONTINUOUS PHOTOCATALYSIS SYSTEMS
}

\author{
N. Arecrachakul ${ }^{1}$, S. Vigneswaran ${ }^{1}$, J. Kandasamy ${ }^{1}$ and C. Duangduen ${ }^{2}$ \\ ${ }^{1}$ Faculty of Engineering, University of Technology, Sydney, P.O. Box 123, Broadway, NSW \\ 2007, Australia \\ ${ }^{2}$ Rajamangala University of Technology, Thanyaburi, Pathumtani, Thailand
}

* Corresponding author Tel.: +612-9514 2641, Fax: +612-9514 2633, Email: s.vigneswaran@uts.edu.au

\begin{abstract}
Photocatalytic oxidation is an emerging technology in water and wastewater treatment. Photocatalysis often leads to complete degradation of organic pollutants without the need for chemicals. This study investigated the degradation of humic substances in water using photocatalysis systems coupled with physio-chemical processes such as adsorption and/or flocculation. Dissolved Organic Carbon (DOC) removal of $\mathrm{PAC}^{-\mathrm{TiO}_{2}}$ was improved by a factor of two to three times compared with $\mathrm{TiO}_{2}$ alone. Solid Phase Micro Extraction (SPME)/Gas Chromatograph (GC) flame ionisation detector (FID) was used to investigate intermediates of photocatalytic oxidation in a batch reactor with $\mathrm{TiO}_{2}$ alone and with powder activated carbon (PAC) with $\mathrm{TiO}_{2}$. GC peaks showed that $\mathrm{PAC}-\mathrm{TiO}_{2}$ adsorbed some by-products which were photo-resistant and prevented the reverse reaction that occurred when $\mathrm{TiO}_{2}$ was used alone. The two other types of photocatalytic reactors used were the continuous photocatalytic reactor and recirculated photocatalytic reactor. The results show that the recirculated reactor had the highest efficiency in removing organic matter in a short photo-oxidation (detention) time of less than 10 min. The use of $\mathrm{PAC}-\mathrm{TiO}_{2}$ in recirculated continuous reactor resulted in $80 \%$ removal of organic matter even when it was operated for a short detention time and allowed the use of a smaller dose of $\mathrm{TiO}_{2}$.
\end{abstract}

Key words: photocatalytic oxidation, humic substances, Gas Chromatograph, flame 
ionisation detector, continuous reactor, recirculated continuous reactor.

\section{INTRODUCTION}

Natural organic matter (NOM) originates from the contact of water with dead and living organic matter as part of the hydrologic cycle, and is a fundamental component of aquatic ecosystems. NOM is important in water treatment processes as it produces harmful byproducts with oxidants, increases chemical costs and reduces water quality during distribution. NOM consists of humic substances (humic and fulvic acids) and non-humic materials including proteins, polysaccharides, and other more labile components [1]. Humic substances are a major organic residue of decaying organic matter. Fulvic acid has lower molecular weight (MW), higher oxygen and lower carbon content and contains more functional groups of an acidic nature, particularly $\mathrm{COOH}$. The detailed properties of humic and fulvic acid may differ depending on the location and are related to the origin of source material and the different degradation pathways.

The pollutant characteristics of NOM include its ability to form complexes with heavy metals and organic micro pollutants, promotes biological growth in water distribution systems, promotes corrosion in water distribution systems and causes a discolouring of water. It can interfere with water treatment processes, as NOM can affect the stability and removal of other colloids and particles and may increase the need for disinfectant dosing. Further, it is well recognised that a high level exposure in the short term by ingestion may lead to an increased likelihood of an acute toxic syndrome, [2].

Chlorine reacts with humic substances and forms disinfection by-products (DBPs) such as trihalomethanes (THM), haloacetic acids (HAA), etc, which are potentially harmful, and even 
carcinogenic to humans [3]. Further the presence of organic contaminants may degrade the ion-exchange capacity and serve as a nutrient source for biological growth, [2].

Various water treatment processes can either directly or indirectly and, to varying degrees, remove aquatic organic matter from raw water, depending on their operational conditions and the specific characteristics of the NOM present in water such as molecular weight distribution (MWD), carboxylic acidity, and humic substances content [4]. Conventional water treatment processes such as coagulation/ flocculation and carbon adsorption have been generally used as pre-treatment to remove NOM. However, it should be noted that these treatment processes will not remove NOM to a required level. NOM with the highest carboxylic acidity and hence the highest charge density compounds are generally difficult to be removed by conventional treatment [4]. Furthermore, a study of the effect of natural organic matter on powdered activated carbon adsorption revealed that the adsorptive capacity of PAC was reduced in the presence of NOM [5].

Advanced oxidation processes are treatment processes that can degrade low molecular weight herbicides pesticides and disinfection by-products [5-9]. Another study on removal of humic substance using $\mathrm{H}_{2} \mathrm{O}_{2} / \mathrm{UV}$ show that the process was not efficient and led to only $9 \%$ removal in terms of organic carbon, [10]. This was explained as the structural changes in the composition of the humic substance such as the transformation of aromatic fractions into aliphatic fractions and conversion of humic fractions to non-humic fractions, without significant conversion of organic matter to carbon dioxide [10].

The photocatalytic degradation of 4-chlorophenol with a suspended mixture of titania and of activated carbon (AC) was conducted, [11]. Their result showed that the degradation of 4 chlorophenol demonstrated an increase of the first order rate constant by a factor of 2.4 with a 
titania mix with activated carbon and, the main intermediate products (hydroquinone and benzoquinone) were found in smaller quantities and during a much smaller lifetime [11].

In this study, the combined heterogeneous photocatalysis with adsorption process was investigated to improve the removal of by-products of photocatalysis oxidation. The efficiency of photocatalysis systems in removing humic substance from water was investigated. The study included the use of $\mathrm{TiO}_{2}$ coupled with PAC in a batch reactor, continuous reactor and recirculated continuous flow reactor. The organic removal rate, measured in terms of dissolved organic carbon (DOC), was used to quantify the efficiency of the photocatalysis system.

\section{EXPERIMENTAL UNITS, MATERIALS AND ANALYSIS}

$\underline{\text { Photocatalysis batch reactor }}$

The batch reactor (Figure 1) was used to find the optimum levels of $\mathrm{TiO}_{2}, \mathrm{pH}$ and the PAC concentrations to be used with $\mathrm{TiO}_{2}$. The photocatalysis was conducted with powdered P25 Degussa $\mathrm{TiO}_{2}$. The product name of the humic substance used in experimentation is Biohumic from the Bioiberica Company (Spain). For convenience, it is referred as humic substance in subsequent sections. The UV lamps used in the batch reactor experiments are G8T5 germicidal lamps from Sankyo Denki which can transmit UV rays at $253.7 \mathrm{~nm}$. The reactor was cooled by circulating water around the reactor as temperatures above $80^{\circ} \mathrm{C}$ leads to a reduction in reaction rates[12]. The batch reactor was covered with aluminium foil at all times during operation.

\section{Photocatalysis continuous reactors}

The photocatalysis continuous reactor (Figure 2) was used to find the optimum detention time 
for the photo oxidation of humic substance. The three reactors L1, L2 and L3 shown in Figure 2 are single lamp reactor. The UV lamps are the same as those used in the batch reactor experiments. The volume of each reactor is $70 \mathrm{~mL}$ giving a total volume for the continuous reactor system of $210 \mathrm{~mL}$. Humic solution (humic substance) and $\mathrm{TiO}_{2}$ were injected directly into a holding tank (T1 in Figure 2) filled with 5L of tap water. After mixing, the tank T1 contained $10 \mathrm{mg} / \mathrm{L}$ DOC and $2 \mathrm{~g} / \mathrm{L}$ of $\mathrm{TiO}_{2}$. This solution was then fed through the continuous reactor using a pump which could operate at a variable rate thereby allowing the flow rate (Q1) to be controlled to different rates.

\section{$\underline{\text { Recirculated Photocatalysis continuous reactors }}$}

The continuous reactor system consisted of three stainless steel reactors (L1, L2 and L3 in Figure 3) each with a volume of $70 \mathrm{~mL}$. $\mathrm{TiO}_{2}$ was dosed directly into a holding tank (T1) containing $5 \mathrm{~L}$ of stock solution. The solution was mixed with a magnetic stirrer and the concentration of humic substance in the stock solution was adjusted to $10 \mathrm{mg} / \mathrm{L}$. In some experiments, a PAC dose of $0.05 \mathrm{~g} / \mathrm{L}$ was added. Air sparging was also provided at a rate of 3.3 VVM (air volume/solution volume/minute). The same rate was used for batch and recirculated continuous reactor. The solution was fed by a pump to a circulation tank (T2). The temperature in the circulation tank was controlled by a thermoline. The solution containing $\mathrm{TiO}_{2}$ and PAC (if present) was pumped to the continuous photo-catalytic reactor at flow rates of 20 and $40 \mathrm{~mL} / \mathrm{min}$. It was circulated in the photo-catalytic reactor at a flow rate (Q2) of $150 \mathrm{~mL} / \mathrm{min}$ to prevent the settling of $\mathrm{TiO}_{2}$ and $\mathrm{PAC}$ (if present) within the reactor. The effluent flow rate (Q1) was adjusted to the desired detention time. The detention time is equal to the volume of the photo-catalytic reactor divided by Q1

\section{$\underline{\text { Analysis }}$}

The DOC was measured using the Multi N/C 2000 analyser (Analytik Jena AG). The sample 
was oxidised into end products in a combustion tube at high temperatures.

A Varian Gas Chromatograph 3400E (GC) equipped with a flame ionisation detector (FID) and a DB-5 column of $0.32 \mathrm{~mm}$ diameter (J\&W, Folsom, CA) was utilised for studying the intermediaries of photo-oxidation. The stationary phase in the column consisted of crosslinked surface bonded 5\% phenyl methyl-polysiloxane with a non-bonded film thickness of $100 \mu \mathrm{m}$. The system was operated using helium as the carrier gas with a linear velocity of 1 $\mathrm{ml} / \mathrm{min}$. The injector and detector temperatures were set at $280^{\circ} \mathrm{C}$. The only modification to the GC was the installation of a 0.75 -mm diameter splitless glass inlet liner to increase the linear velocity of the analyte and to leave less space for the analyte to reabsorb onto the Solid Phase Micro Extraction (SPME) fibre. Both these effects enhances desorption from the fibre. Humic substance with a higher concentration of $100 \mathrm{mg} / \mathrm{L}$ was used in these experiments. The temperature in the column was increased in the following manner. The column temperature was first kept at $40^{\circ} \mathrm{C}$ for 5 minutes, then increased to $150^{\circ} \mathrm{C}$ where the temperature was held constant for 10 minutes, then increased at $5^{\circ} \mathrm{C} /$ minutes to $200{ }^{\circ} \mathrm{C}$ (where it was held for 10 min), then increased at $1{ }^{\circ} \mathrm{C} /$ minute to $210^{\circ} \mathrm{C}$ (where it was held for 10 minutes), then increased at $10^{\circ} \mathrm{C} /$ minutes to $270{ }^{\circ} \mathrm{C}$ (where it was held for 10 minutes), and finally to $280^{\circ} \mathrm{C}$ at a rate of increase of $10^{\circ} \mathrm{C}$ per minute (where it was held for 10 minutes). The total run time was $55 \mathrm{~min}$. The detector gases were hydrogen and air at flows of 4 and $120 \mathrm{~mL} / \mathrm{min}$, respectively.

Initial experiments focused on determining the time at which equilibrium was established between the analytes in the stationary and aqueous phases. Triplicate solutions were extracted for periods of time ranging from 10-60 min. The equilibrium times were determined by inspection of the concentration of the humic substance and it was observed that there was 
almost not change of the peak height after $30 \mathrm{~min}$. The 30 min period in $40 \mathrm{ml}$ vial was the optimum time. The optimisation of the desorption temperature and time was investigated by considering the amount desorbed from fibres after extraction of analytes from a solution of known concentration and the subsequent carryover at a range of temperatures and time periods.

\section{Experiments}

A humic substance concentration of $10 \mathrm{ppm}$ was used for all experiments. 1.5L of tap water was added to the batch reactor and stirred with a magnetic stirrer. Humic substance was added as required to bring its concentration in the batch reactor to about 10ppm. For the continuous reactor, $5 \mathrm{~L}$ of tap water was added to the storage tank. The humic substance was injected directly into the storage tank and stirred with a magnetic stirrer to bring the humic substance concentration to about 10ppm. An initial TOC measurement was taken for all experiments before treatment commences.

Experiments on flocculation were carried out with ferric chloride $\left(\mathrm{FeCl}_{3}\right)$. Each container held 2L of tap water and $10 \mathrm{mg} / \mathrm{L}$ of humic substance. Initial TOC measurements were taken first before $\mathrm{FeCl}_{3}$ was added. Different amounts of $\mathrm{FeCl}_{3}$ were added into each container to achieve concentrations between $30-150 \mathrm{mg} / \mathrm{L}$. The samples were then stirred rapidly for 1 minute at 100rpm, followed by 20 minutes of slow mixing at 30rpm, and were allowed to settle for 30 minutes. Samples from each container was then taken and analysed for TOC. The samples were then left for flocs to settle after which $1.5 \mathrm{~L}$ of the supernatant was extracted for photocatalysis in the batch reactor. Only solution with a concentration of 50 and $60 \mathrm{mg} / \mathrm{L}$ of $\mathrm{FeCl}_{3}$ were used with photo catalytic batch reactor since $50 \mathrm{mg} / \mathrm{L}$ was found to be the optimum dose. $\mathrm{TiO}_{2}$ was added to the supernatant at a concentration of $2 \mathrm{~g} / \mathrm{L}$. 
Another set of experiments was conducted to study the adsorption kinetics of PAC. Clean and dry PAC was added into 2L beakers containing humic substance to achieve concentrations of 0.1, 0.5, 1 and $2 \mathrm{~g} / \mathrm{L}$ of PAC. The solution was mixed well using a mechanical stirrer at 130 rpm for 3 hours. During the experiments, samples were taken periodically to measure the TOC concentration. After stirring, the sample was left for 2 hours for PAC to settle after which $1.5 \mathrm{~L}$ of the supernatant was extracted.

\section{RESULTS AND DISCUSSIONS}

\section{FLOCCULATION AND FLOCCULATION-PHOTOCATALYTIC REACTION}

Figure 4 shows the percentage of $\mathrm{DOC}$ removed by $\mathrm{FeCl}_{3}$ acting as coagulant. The optimum dose was $50 \mathrm{mg} / \mathrm{L}$ which yielded a removal of $84 \%$ of humic substance. Large doses of the coagulant (100 and $150 \mathrm{mg} / \mathrm{L}$ of $\mathrm{FeCl}_{3}$ ) lead to very low acidic $\mathrm{pH}$. Iron species become more positively charged at lower $\mathrm{pH}$. After humic substance reacts with iron species, a fraction of the complex undergo charge reversal (from negative to positive charge), which prevent the complexes of $\mathrm{Fe}^{3+}$ and colloids of humic substance from being removed [13,14].

Figure 5 shows the results of flocculation with $50 \mathrm{mg} / \mathrm{L}$ and $60 \mathrm{mg} / \mathrm{L}$ followed a period of photocatalysis. A sample of the supernatant was extracted for TOC measurement immediately after the slow mixing of the flocculation process and another after 1 hour when settling had occurred. Further samples were extracted for TOC measurement during the period of photocatalysis. There was little change in DOC in the period after flocculation and settling. The removal of humic substance decreased where an amount of $\mathrm{FeCl}_{3}(60 \mathrm{mg} / \mathrm{L})$ in excess of the optimum dose was used. The fluctuation of DOC during the photocatalysis period may be attributed to the TOC measurement. The fluctuation may also be attributed to the reverse 
reaction where the reaction of hydroxyl radicals increases the portion of humic acids with less hydrophobic, less adsorbing, and less aromatic characters, in general. In the presence of iron binding compound such as humic substance, it can alter the rate constant and change the formation rate of hydroxyl radical [15].

\section{EFFECT OF TIO $_{2}$ CONCENTRATION ON PHOTOCATALYTIC REACTION}

Two sets of experiments were conducted with a batch reactor to identify the effect of various dosages of $\mathrm{TiO}_{2}$ on the photocatalytic reaction. One set of experiments were carried out without UV treatment while the second set of experiments were conducted with UV treatment

The first set studied the affinity of humic substance to $\mathrm{TiO}_{2}$ in batch equilibrium experiments without the application of UV (Figure 6). The experiments was carried out by mixing $1.5 \mathrm{~L}$ solution of humic substance in a batch reactor at a neutral $\mathrm{pH}$ of 7.2 with varying amounts of $\mathrm{TiO}_{2}$ doses between 0.5 to $2.0 \mathrm{~g} / \mathrm{L}$. The result (Figure 6) shows that humic substance was adsorbed quickly onto the $\mathrm{TiO}_{2}$ particles. DOC removal was around 10 to $15 \%$ after 15 min and nearly constant up to 2 hours.

The second set of experiments used $10 \mathrm{mg} / \mathrm{L}$ of humic substance with different concentrations of $\mathrm{TiO}_{2}\left(0 \mathrm{~g} / \mathrm{L}\left(\mathrm{UV}\right.\right.$ treatment without $\left.\mathrm{TiO}_{2}\right), 0.5 \mathrm{~g} / \mathrm{L}, 2.0 \mathrm{~g} / \mathrm{L}, 3.0 \mathrm{~g} / \mathrm{L}$ and $\left.4.0 \mathrm{~g} / \mathrm{L}\right)$ and $\mathrm{UV}$. The $\mathrm{TiO}_{2}$ powder was added directly into the batch reactor and stirred with a magnetic stirrer. Samples were taken after $10 \mathrm{~min}, 30 \mathrm{~min}, 1 \mathrm{hr}, 2 \mathrm{hr}$, $3 \mathrm{hr}$, $4 \mathrm{hr}$, $5 \mathrm{hr}$, 6hr and $6.5 \mathrm{hr}$ of treatment,. The results (Figure 7) show that direct photolysis (UV treatment without $\mathrm{TiO}_{2}$ ) of humic substance provides no significant removal of DOC. In fact the results shows a slight increase in TOC (DOC) which could have been induced by the slow evaporation of water during the experimental period[16]. With different dose of $\mathrm{TiO}_{2}$, humic substance degrades quickly during the first 10 minutes of operation following which a reverse reaction was observed after 
20 minutes. The degradation with $\mathrm{TiO}_{2}$ during the initial period (10 minutes) is related to the amount of $\mathrm{TiO}_{2}$ in suspension where a smaller concentration of $\mathrm{TiO}_{2}$ resulted in a lower degradation rate. Following this initial period there was no significant degradation of humic substance during the 6 hours. After 6 hours of retention time, humic substance removal in terms of DOC was $25 \%$ (for $0.5 \mathrm{~g} / \mathrm{L}$ of $\mathrm{TiO}_{2}$ ), $43 \%$ (for $2 \mathrm{~g} / \mathrm{L}$ of $\mathrm{TiO}_{2}$ ), $60 \%$ (for $3 \mathrm{~g} / \mathrm{L}$ of $\mathrm{TiO}_{2}$ ), and $56 \%$ (for $4 \mathrm{~g} / \mathrm{L}$ of $\mathrm{TiO}_{2}$ ).

These results revealed that a concentration of $\mathrm{TiO}_{2}>3 \mathrm{~g} / \mathrm{L}$ retards the reaction because the penetration of UV light was impeded by the $\mathrm{TiO}_{2}$ in suspension and the consequent reduced formation of electron/hole pairs and active sites [17]. Previous researchers also have not obtained the complete mineralisation of humic acid with $\mathrm{UV} / \mathrm{TiO}_{2}[18,19]$. Reverse reaction was mainly observed during the period between 20 minutes to 4 hours. Reverse reaction is due to large MW being broken down into small MW during the photocatalytic process. Therefore, to alleviate the reverse reaction, treatment should incorporate measures to remove the large MW before the photocatalytic reaction.

For the $\mathrm{TiO}_{2}$ dose of $2 \mathrm{~g} / \mathrm{L}$ a SPME/GC FID analysis was carried out on samples at various times between 5-240 minutes to determine the intermediaries of photo-oxidation. A concentration of $100 \mathrm{mg} / \mathrm{L}$ of humic substance was used instead of $10 \mathrm{mg} / \mathrm{L}$ due to detection limit of Flame ionisation detector (FID).

The study of GC/SPME demonstrated that the humic substance is converted to several photoproducts during photo-oxidation (Figure 8). The cleavage of large MW of humic substances was confirmed by the SPME/GC FID. Unfortunately, due to the complex nature of the byproducts, GC FID did not allow the identification of individual oxidation intermediates of humic substance. However, it provided some idea of the appearance of these complex 
compounds (intermediaries) during the photo-catalytic process.

These results indicate that the photo-degradation of humic substance led to the production of smaller MW organic intermediaries. Some are easily degraded by $\mathrm{TiO}_{2} / \mathrm{UV}$ (retention time (rt.) of 18.3). Other compounds (such as rt. of 20.21 and 17.40) are possibly photo-resistant compounds and hardly degrade (Figures 8a). The photo-resistant compounds that occur during photo-oxidation may lead to an increase of DOC level. However after 4 hours of operation time the concentration of photo-products seemed to have reduced. A comparison of Figures $8 \mathrm{a}, 8 \mathrm{~b}$ and $8 \mathrm{c}$ shows peaks of photo products are lower in Figure 8c compared to the corresponding peaks observed in Figure 8a and 8b. A lower peak, or more correctly the area under the peak, corresponds to a lower concentration. It is estimated there are the incomplete degradation is equivalent to about $35 \%$ of the initial humic substance as shown by DOC levels in Figure 7.

\section{EFFECT OF pH ON PHOTOCATALYTIC REACTION}

A set of experiments was carried out in a batch reactor in order to identify the effects of $\mathrm{pH}$ on photocatalysis. Each experiment was conducted at different $\mathrm{pH}$ values of 3.6, 4.6, 7.2, 9 and 10. The $\mathrm{pH}$ was altered after humic substance was injected into the batch reactor by the addition of either $\mathrm{NaOH}$ or $\mathrm{HCl}$ and monitored with a $\mathrm{pH}$ meter. After the required level of $\mathrm{pH}$ was reached, $2.0 \mathrm{~g} / \mathrm{L}$ of $\mathrm{TiO}_{2}$ (which is the optimum level of $\mathrm{TiO}_{2}$ ) was added directly to the batch reactor and stirred with a magnetic stirrer. Initial samples were taken after the $\mathrm{pH}$ was adjusted. Further samples were taken after 10min, 30min, $1 \mathrm{hr}$, $2 \mathrm{hr}$, 3hr and $4 \mathrm{hr}$ of treatment.

Figure 9 presents the effect of $\mathrm{pH}$ on the photocatalytic reaction of humic substance. It was 
observed that the highest level of humic substance removal occurred at $\mathrm{pH} 3.2$ and 6 followed by $\mathrm{pH}$ 9.0. At $\mathrm{pH} 10.0$ there is a significant amount of reverse reaction. The results showed that degradation rates were strongly dependent on $\mathrm{pH}$ due to the $\mathrm{pH}$-dependent adsorption of humic substance on $\mathrm{TiO}_{2}$. In this study, in acidic media (pH 3.2), DOC removal was up to 78\% compared with 20\% DOC removal in basic media and $40 \%$ DOC removal without pH adjustment. These results can be explained by the surface charge of the $\mathrm{TiO}_{2}$ surface at different $\mathrm{pH}$ values. In acidic media $(\mathrm{pH}<7)$, the $\mathrm{TiO}_{2}$ surface is positively charged. This improves the adsorption of $\mathrm{TiO}_{2}$ particles. Whereas if the $\mathrm{pH}$ is too high, there will be no adsorption by the $\mathrm{TiO}_{2}$ particles, [18]. However a high pH can increase the photocatalytic reaction rate and the $\mathrm{TiO}_{2}$ quantum yield, thus improving the degradation of humic substance (Table 1). This explains why humic substance removal was higher at $\mathrm{pH} 9$ than at neutral conditions. $[18,19]$. However, the need to adjust the $\mathrm{pH}$ prior to and after the treatment is a major impediment. Furthermore, the humic substance removal rate is only slightly higher between alkaline $\mathrm{pH}(9)$ and neutral $\mathrm{pH}$.

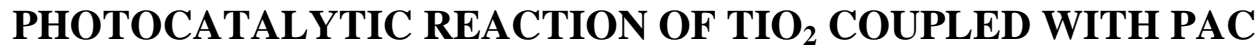

The PAC batch adsorption experiments (Figure 10) show that the DOC removal increases by up to $80 \%$ with higher concentrations of PAC. However, the DOC removal efficiency was not significantly improved beyond a concentration of $1 \mathrm{~g} / \mathrm{L}$ of PAC dose.

After PAC adsorption, a 2 litres of water sample was left for 3 hours until the PAC had completely settled. 1.5 litres of the supernatant was used together with $\mathrm{TiO}_{2}$ (concentration of $2 \mathrm{~g} / \mathrm{L}$ ) in a photo-catalytic batch reactor. The results shown in Figure 11 demonstrate the importance of post-photocatalysis in the degradation of humic substances. Following photocatalysis removal of humic substance further increased to between 74-83\% (Figure 11). 
A set of experiments was conducted at different concentrations of $\mathrm{TiO}_{2}(1.0 \mathrm{~g} / \mathrm{L}, 2.0 \mathrm{~g} / \mathrm{L}$ and 3.0g/L), each combined with a small additional dose of PAC $(0.05 \mathrm{~g} / \mathrm{L})$. These were used to investigate whether PAC could reduce the concentration of $\mathrm{TiO}_{2}$ required for treatment [20]. $\mathrm{TiO}_{2}$ and PAC were added directly into the batch reactor and stirred with a magnetic stirrer. Samples were taken after 10min, 30min, $1 \mathrm{hr}, 2 \mathrm{hr}$, $3 \mathrm{hr}$ and $4 \mathrm{hr}$ of treatment. Figure 12 shows further improvement in DOC removal when PAC was added together with $\mathrm{TiO}_{2}$ in the photo reactor. The results showed that 75\% DOC removal of $2 \mathrm{~g} / \mathrm{L}$ and $3 \mathrm{~g} / \mathrm{L}$ in 10 min detention time of $\mathrm{TiO}_{2}$ and PAC compared with $40 \%$ and 50\% DOC removal with $2 \mathrm{~g} / \mathrm{L}$ and $3 \mathrm{~g} / \mathrm{L}$ of $\mathrm{TiO}_{2}$ alone.

SPME/ GC FID equipped with DB-5 column was used to investigate the photo products during the photo-catalytic reaction. Using a small amount of $\mathrm{PAC}$ coupled with $\mathrm{TiO}_{2}$ revealed a superior removal of humic substance (DOC). The manner in which intermediate photoproducts evolve and transform was demonstrated by the GC FID peak. These results can be summarised in the following way. The photo resistant by products was adsorbed on PAC$\mathrm{TiO}_{2}$ surface as shown in GC peak results (Figure $13 \mathrm{a}, \mathrm{b}, \mathrm{c}$ ). The GC peak after 210 min of PAC- $\mathrm{TiO}_{2}$ revealed only a rt. of 19.5 min compared with several peaks (rt. of 17.4, 19.2, 20.2) of by products after 240 min operation time when using $\mathrm{TiO}_{2}$ alone (Figure 8c). From DOC measurements, it is estimated that less than $25 \%$ of the initial material remained (Figure 12). Humic substances are widely known as the major organic precursors for trihalomethane formation THMFs during the chlorination processes, [3]. From these results, the use of $\mathrm{TiO}_{2}-$ PAC demonstrated superior removal of humic substance with shorter contact time and higher removal efficiencies compared with using $\mathrm{TiO}_{2}$ alone. It is suggested that during the PAC$\mathrm{TiO}_{2}$ batch process humic substance was removed immediately without forming a large amount of intermediate macro-molecules of humic substance. 


\section{PHOTOCATALYTIC CONTINUOUS REACTOR}

This set of experiments was conducted with a continuous photocatalytic reactor, Figure 2. These experiments were run at different flowrates $(10 \mathrm{~mL} / \mathrm{min}, 20 \mathrm{~mL} / \mathrm{min}, 30 \mathrm{~mL} / \mathrm{min}$ and $40 \mathrm{~mL} / \mathrm{min}$ ) to investigate the effect of detention time on photocatalytic reaction. $2.0 \mathrm{~g} / \mathrm{L}$ of $\mathrm{TiO}_{2}$ was added directly in the container holding the humic substance. Samples were taken to measure TOC after 5min, 20min, 40min and 1 hr of treatment.

Figure 14 showed the humic substance removal efficiency of a photocatalytic continuous reactor at different detention times of $21 \mathrm{~min}$ (equivalent to a flow rate of $10 \mathrm{~mL} / \mathrm{min}$ ), 10.5 $\min (20 \mathrm{~mL} / \mathrm{min}), 7 \mathrm{~min}(30 \mathrm{~mL} / \mathrm{min})$ and $5.2 \mathrm{~min}(40 \mathrm{~mL} / \mathrm{min})$. Better results were achieved at longer detention times as there was more contact time. At a detention time of $10.5 \mathrm{~min}$, the humic substance removal with a $\mathrm{TiO}_{2}$ dose of $2 \mathrm{~g} / \mathrm{L}$ was about $60 \%$. However, the TOC removal was $10 \%$ lower at a detention time of $21 \mathrm{~min}$. It was attributed to the settling of $\mathrm{TiO}_{2}$ particles and accumulation in the first reactor during the longer detention time.

The continuous photo-catalytic reactor was also used with a combination of $0.05 \mathrm{~g} / \mathrm{L}$ of PAC and $2 \mathrm{~g} / \mathrm{L}$ of $\mathrm{TiO}_{2}$ (Figure 15). The flow rate varied from 10 to $40 \mathrm{~mL} / \mathrm{min}$ corresponding to a detention time of $20.1 \mathrm{~min}$ to $5.2 \mathrm{~min}$. The results also indicate that the photo-catalytic adsorption hybrid system removed a significant amount of humic substance (80\% TOC removal) within a short contact time.

\section{RECIRCULATED PHOTOCATALYTIC CONTINUOUS REACTOR}

In a plug flow reactors the factors for controlling removal rates in heterogeneous catalysis are mass transfer and surface reaction controls. These factors are improved in a high recirculation 
flow rate of $250 \mathrm{~mL} / \mathrm{min}$ where flow is turbulent. The reaction rates are increased as result. This behaviour of turbulent $(\mathrm{Re} \geq 2000)$ plug flow reactor was observed by [21]. Thus, experiments with the recirculating continuous flow reactor (Figure 3) were carried out. 0.5 $\mathrm{g} / \mathrm{L}$ of $\mathrm{TiO}_{2}$ was also used in these experiments. The solution was recirculated (Q2 in Figure 3) at a high speed of $150 \mathrm{~mL} / \mathrm{min}$ by the Masterflex pump to avoid the settling of $\mathrm{TiO}_{2}$ and the uniform dispersion of $\mathrm{TiO}_{2}$ in the solution. The solution was initially left in the dark for a period of 15 min before feeding to the recirculating container. The solution was fed through the circulation tank at the same rate. Effluent was continuously withdrawn by another pump (Q1 shown in Figure 3) from the circulation tank. Samples were taken to measure TOC after 5 min, $10 \mathrm{~min}, 30 \mathrm{~min}$, 40min, $60 \mathrm{~min}, 90 \mathrm{~min}$, and $120 \mathrm{~min}$ of operation time.

Recirculated continuous flow reactor experiments were conducted at $\mathrm{pH} 7.2$ with $0.5 \mathrm{~g} / \mathrm{L}$ of $\mathrm{TiO}_{2}$ alone and with $0.5 \mathrm{~g} / \mathrm{L}$ coupled with PAC $0.05 \mathrm{~g} / \mathrm{L}$. During the initial stage, adsorption occurred in the dark for a period of 15 minutes. During this period, $15 \%$ of humic substance was removed using $\mathrm{TiO}_{2}$ alone and 35\% was removed using $\mathrm{PAC}^{-\mathrm{TiO}_{2}}$ (Figure 16). After the initial dark period, the solution was pumped through a recirculating tank following by a high speed feed through the UV reactor at $250 \mathrm{~mL} / \mathrm{min}$. Samples were taken by direct pumping from recirculated tank at various times. A slight decrease of humic substance equivalent to approximately 20\% DOC removal was observed after 20 minutes of operation time after which there was no further removal.

When a small amount of PAC was added, DOC removal improved upto $80 \%$ in a shorter operation time of less than 10 minutes. This was the point to which activated carbon adsorbed photo-products that were photo-resistant as demonstrated by SPME/ GC FID analysis of batch experiments. 
At the higher withdrawal rate of $40 \mathrm{~mL} / \mathrm{min}$, a similar trend was demonstrated (Figure 17). With $0.5 \mathrm{~g} / \mathrm{L}$ of $\mathrm{TiO}_{2}$ alone, DOC removal was less than $20 \%$ compared with the withdrawal rate of $20 \mathrm{~mL} /$ minute. However there was no significant difference of humic substance removal with $\mathrm{PAC}-\mathrm{TiO}_{2}$.

\section{CONCLUSION}

The type of photocatalysts, $\mathrm{pH}$ and the physio-chemical properties of humic substance such as their photo-products, play major roles in the removal of humic substance. This study showed that in low $\mathrm{pH}(\mathrm{pH} 3.2)$ or acidic media the photocatalytic degradation of humic substances was higher than in basic media ( $\mathrm{pH} 10)$. Furthermore, photo intermediate products play major roles in photocatalytic degradation of humic substances as shown in SPME/GC FID analysis (GC peaks). A small addition of PAC could alleviate this problem and achieve an increase in the removal efficiency of humic substance in a shorter contact time. Experiments with the continuous photocatalysis reactor using $\mathrm{TiO}_{2}$ alone as photocatalyst compared with the use of $\mathrm{TiO}_{2}-\mathrm{PAC}$ as photocatalyst showed that the removal rate for the later was superior with a shorter detention time and higher removal efficiency. 


\section{References}

1. Amy, G., Her, N.G. \& Jarusutthirak, C. (2001). Size Exclusion Chromatography (SEC) with UV, Fluorescence, and On-Line DOC Detection: Fingerprints of Natural (NOM), Algal (AOM), and Wastewater Effluent (EfOM) Organic Matter. In Utilization of NOM characteristics to improve process selection and performance: Workshop results. Retrived: $2^{\text {nd }}$ September, 2004, from http://www.waterquality.crc.org.au/nom/workshop_Oct01.pdf, 37-41.

2. Eikebrokk, B., Gjessing. And Odegaard, H.: 'Why NOM removal is important' AWWA/AWQC workshop, Berlin, 10-12. October, (2001) American Water Works Association.

3. Bowen, W.R. and F. Jenner, Theoretical descriptions of membrane filtration of colloids and fine particles: an assessment and review. Advances in Colloid and Interface Science, (1995). 56: p. 141-200.

4. Collins, M.R., G.L. Army, and C. Steelink, Molecular weight distribution, carboxylic acidity, and humic substances content of aquatic organic matter: Implications for removal during water treatment. ENVIRON. SCI. TECHNOL., (1986). 20(10): p. 1028-1032.

5. Matsui, Y., et al., Effect of natural organic matter on powdered activated carbon adsorption of trace contaminants: characteristics and mechanism of competitive adsorption. Water Research, (2003). 37(18): p. 4413-4424.

6. Calza, P., et al., Photolytic and photocatalytic decomposition of bromomethanes in irradiated aqueous solutions. Applied Catalysis B: Environmental, (1999). 21(3): p. 191-202. 
7. Samanta, S., R.K. Kole, and A. Chowdhury, Photodegradation of metsulfuron methyl in aqueous solution. Chemosphere, (1999). 39(6): p. 873-879.

8. Vulliet, E., et al., Photocatalytic degradation of the herbicide cinosulfuron in aqueous $\mathrm{TiO}_{2}$ suspension. Environ Chem Lett, (2003). 1: p. 62 - 67.

9. Von Gunten, U., Ozonation of drinking water: Part II. Disinfection and by-product formation in presence of bromide, iodide or chlorine. Water Research, (2003). 37(7): p. $1469-1487$.

10. Song, W., et al., Nanofiltration of natural organic matter with H2O2/UV pretreatment: fouling mitigation and membrane surface characterization. Journal of Membrane Science, (2004). 241(1): p. 143-160.

11. Herrmann, J.-M., et al., Solar photocatalytic degradation of 4-chlorophenol using the synergistic effect between titania and activated carbon in aqueous suspension. Catalysis Today, (1999). 54(2-3): p. 255-265.

12. Shon, H.K., et al., Chemical coupling of photocatalysis with flocculation and adsorption in the removal of organic matter. Water Research, (2005). 39(12): p. 25492558.

13. American Water Works Association, Water Quality and Treatment, ed. 3. (1971): McGraw - Hill.

14. Cheng, W.P., F.H. Chi, and R.F. Yu, Effect of phosphate on removal of humic substances by aluminum sulfate coagulant. Journal of Colloid and Interface Science, (2004). 272(1): p. 153-157.

15. Lindsey, M.E. and M.A. Tarr, Quantitation of hydroxyl radical during Fenton oxidation following a single addition of iron and peroxide. Chemosphere, (2000). 41(3): p. 409-417. 
16. Wiszniowski, J., et al., Photocatalytic decomposition of humic acids on TiO2: Part I: Discussion of adsorption and mechanism. Journal of Photochemistry and Photobiology A: Chemistry, (2002). 152(1-3): p. 267-273.

17. Eggins, B.R., F.L. Palmer, and J.A. Byrne, Photocatalytic treatment of humic substances in drinking water. Water Research, (1997). 31(5): p. 1223-1226.

18. Tanaka, S. and Saha, U.K. (1994). Effects of pH on photocatalysis of 2,4,6Trichlorophenol in aqueous TiO2 suspensions. Water Science and Technology, 30(9); 44-57

19. Wang, S., Bahnemann, D.W. \& Dohrmann, J.K. (2001). 'Determination of photonic efficiency and quantum yield of formaldehyde formation in the presence of various TiO2 photocatalysts'. Water Science and Technology, vol. 44, no.5, pp. 279-286

20. Nathaporn, A., et al., Photocatalytic hybrid system in degradation of herbicide (metsulfuron-methy). Water Science and Technology: Water supply, 2006. 6(2): p. 109 $-114$.

21. Scheible, O.K., M.C. Casey, and A. Fondran, National Technical Information Service. (1985), Springfield, V.A.: NITS Publication 86 - 145182 
Table $1 \mathrm{pH}$ and photocatalysis

\begin{tabular}{|c|c|}
\hline \multicolumn{2}{|c|}{ PHOTOCATALYTIC REACTION IN } \\
DIFFERENT $\mathbf{p H}$ \\
\hline $\mathbf{p H}<7$ & $\mathbf{p H}>\mathbf{7}$ \\
\hline High adsorption on & Low adsorption on \\
TiO2 surface & TiO2 surface \\
\hline Low quantum yield & High quantum yield \\
\hline
\end{tabular}




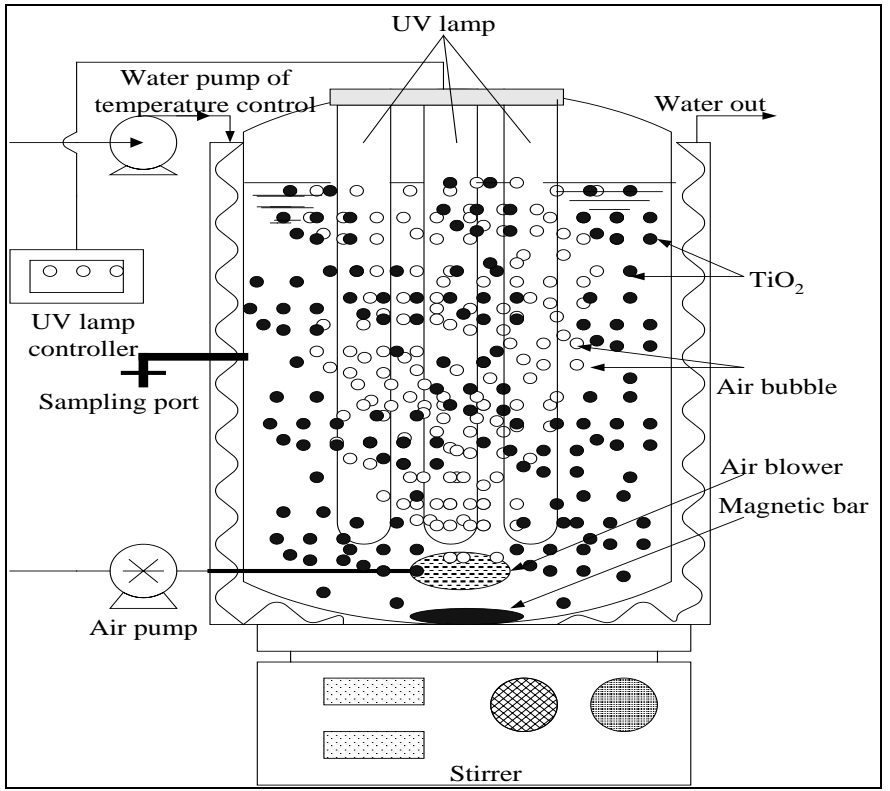

Figure 1 Schematic of the photo-catalytic batch reactor 


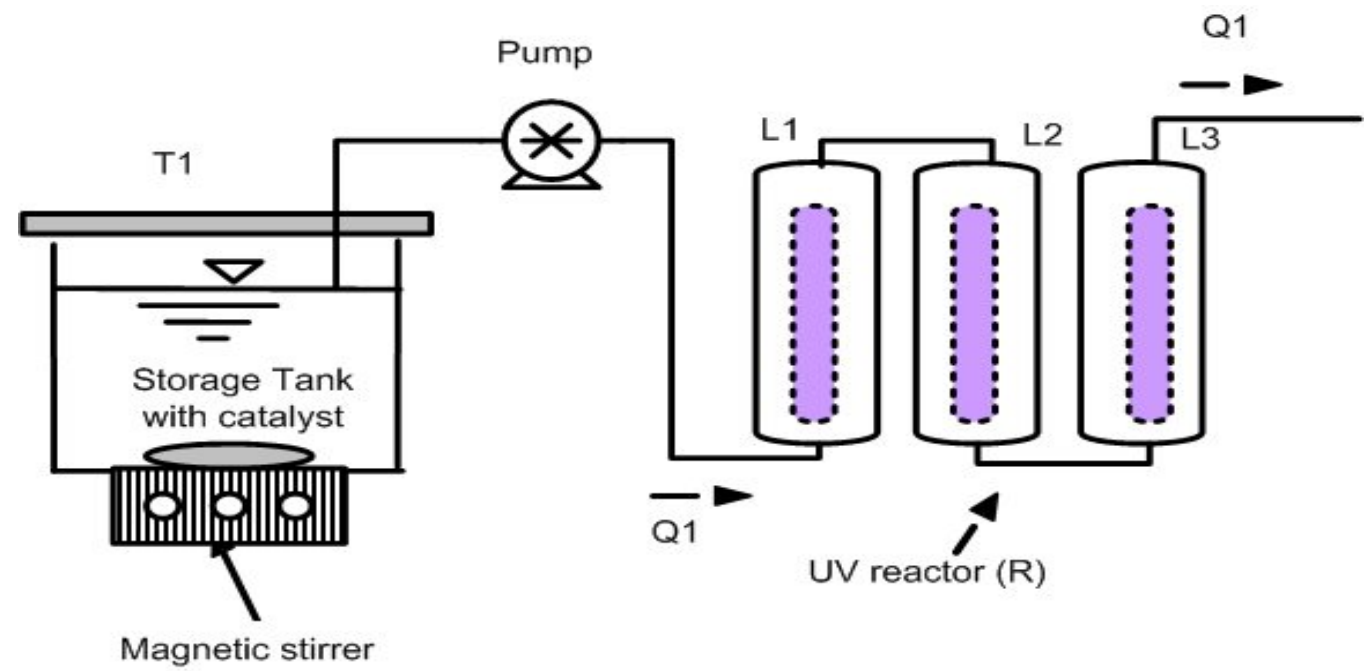

Figure 2 Schematic of continuous reactor (T1: Mixing tank with no light source; Q1: influent and withdrawal rate; R: photo-catalytic reactor unit; L1, L2, L3 are UV lamps of 8 watts each) 


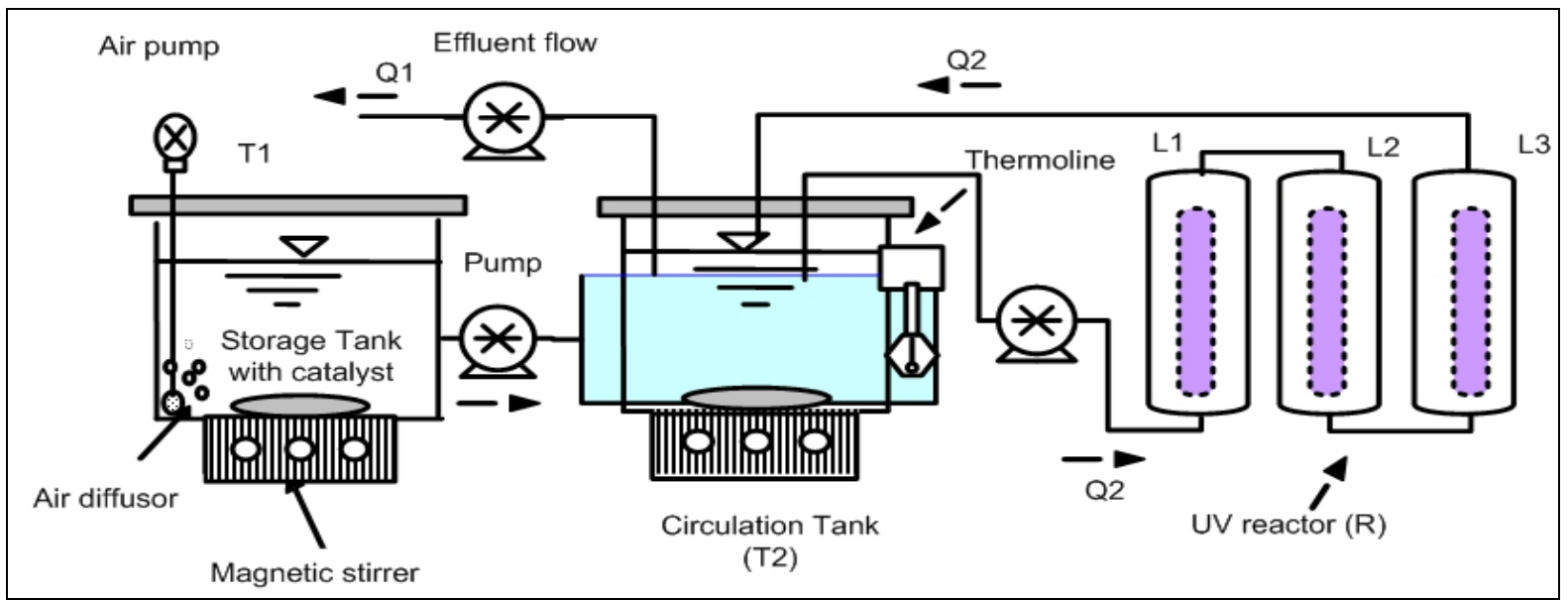

Figure 3 Schematic of the recirculating continuous flow photo-catalytic reactor with the catalyst. (T1: Mixing tank with no light source; Q1: influent and withdrawal rate; Q2: recirculation flow; T2: re- circulation tank; R: photo-catalytic reactor unit; L1, L2, L3 are UV lamps of 8 watts each) 


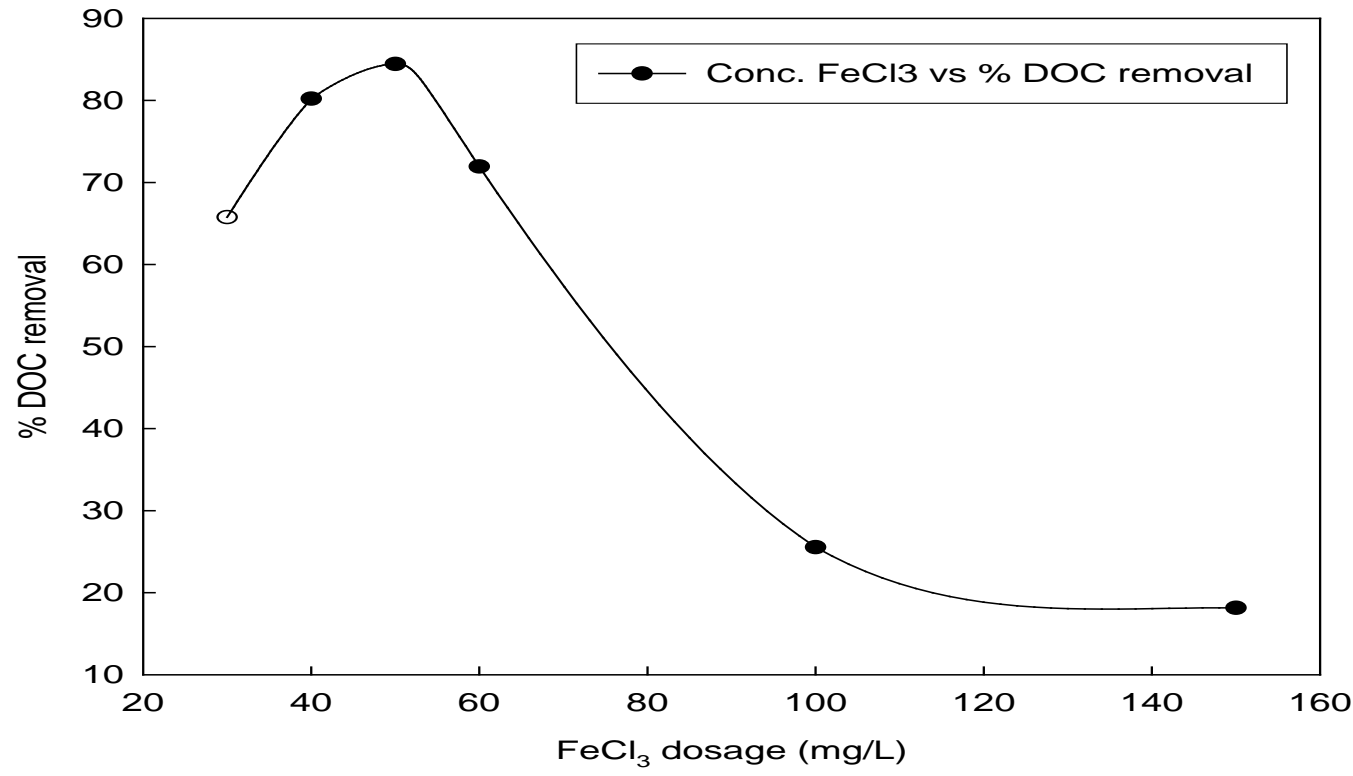

Figure 4. \% DOC removal of humic substances by $\mathrm{FeCl}_{3}$ flocculation (influent $\mathrm{TOC}=10$ $\mathrm{mg} / \mathrm{L})$. 


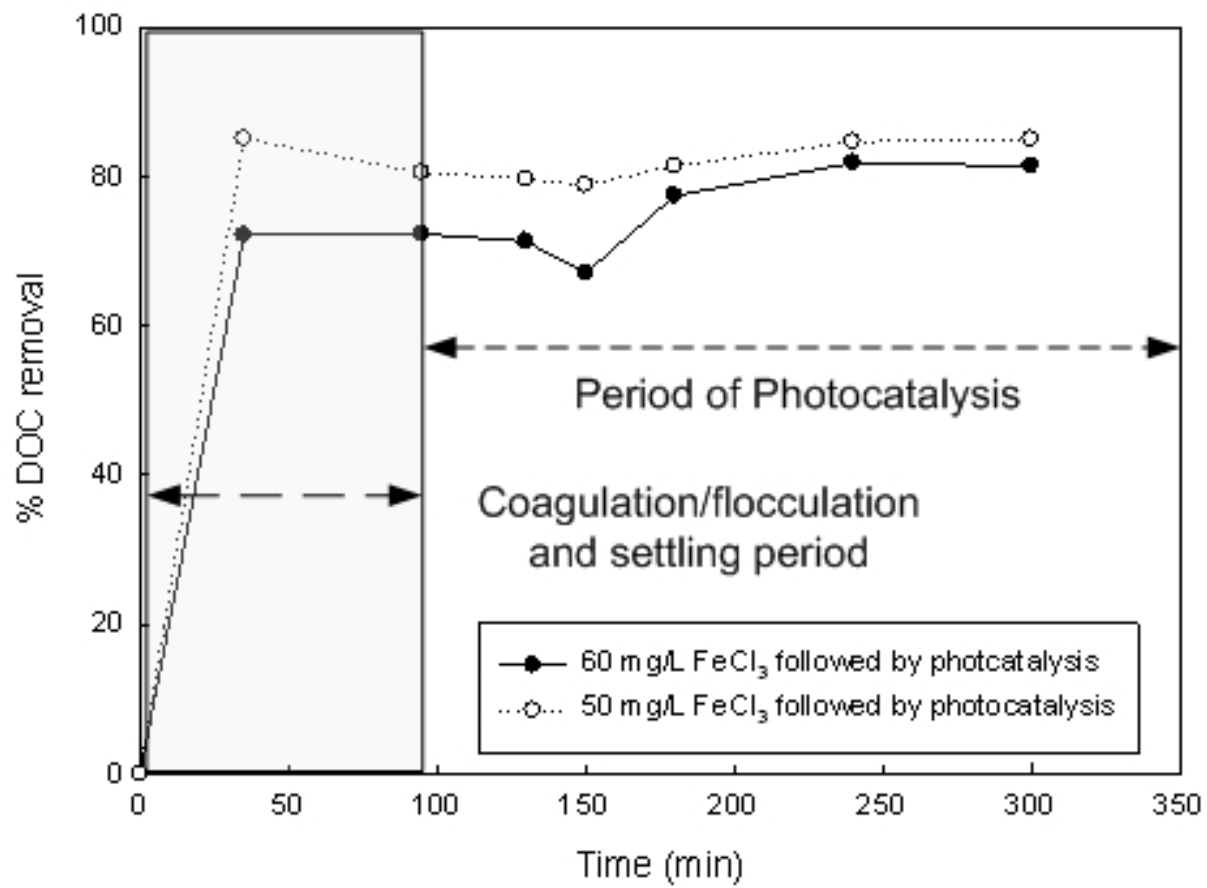

Figure $5 . \mathrm{FeCl}_{3}$ flocculation as a pre treatment followed by photocatalytic reaction (influent TOC = $10 \mathrm{mg} / \mathrm{L}, 2 \mathrm{~g} / \mathrm{L} \mathrm{TiO}_{2}$ ). 


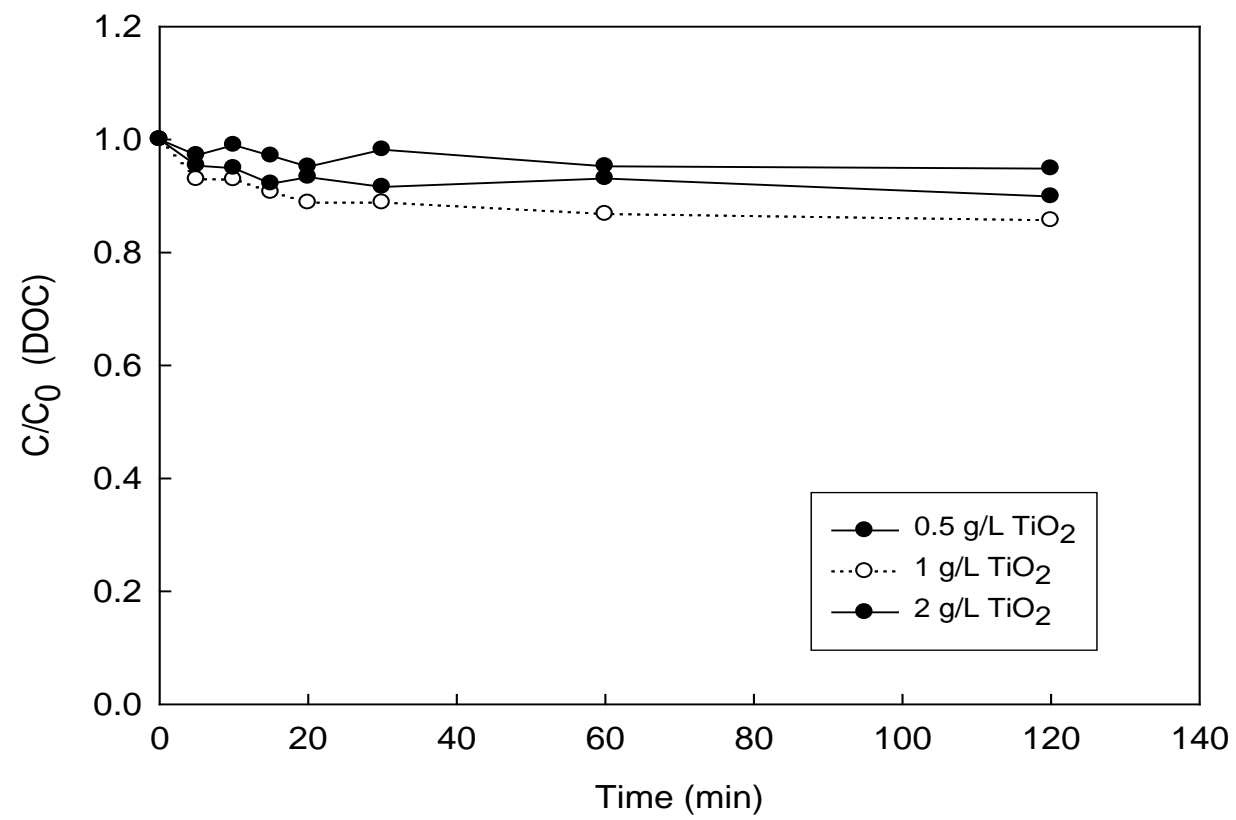

Figure 6 Removal of humic substances (DOC) with different concentration of $\mathrm{TiO}_{2}$ without $\mathrm{UV}$ in a batch reactor. (Influent TOC $=10 \mathrm{mg} / \mathrm{L}$ ) 


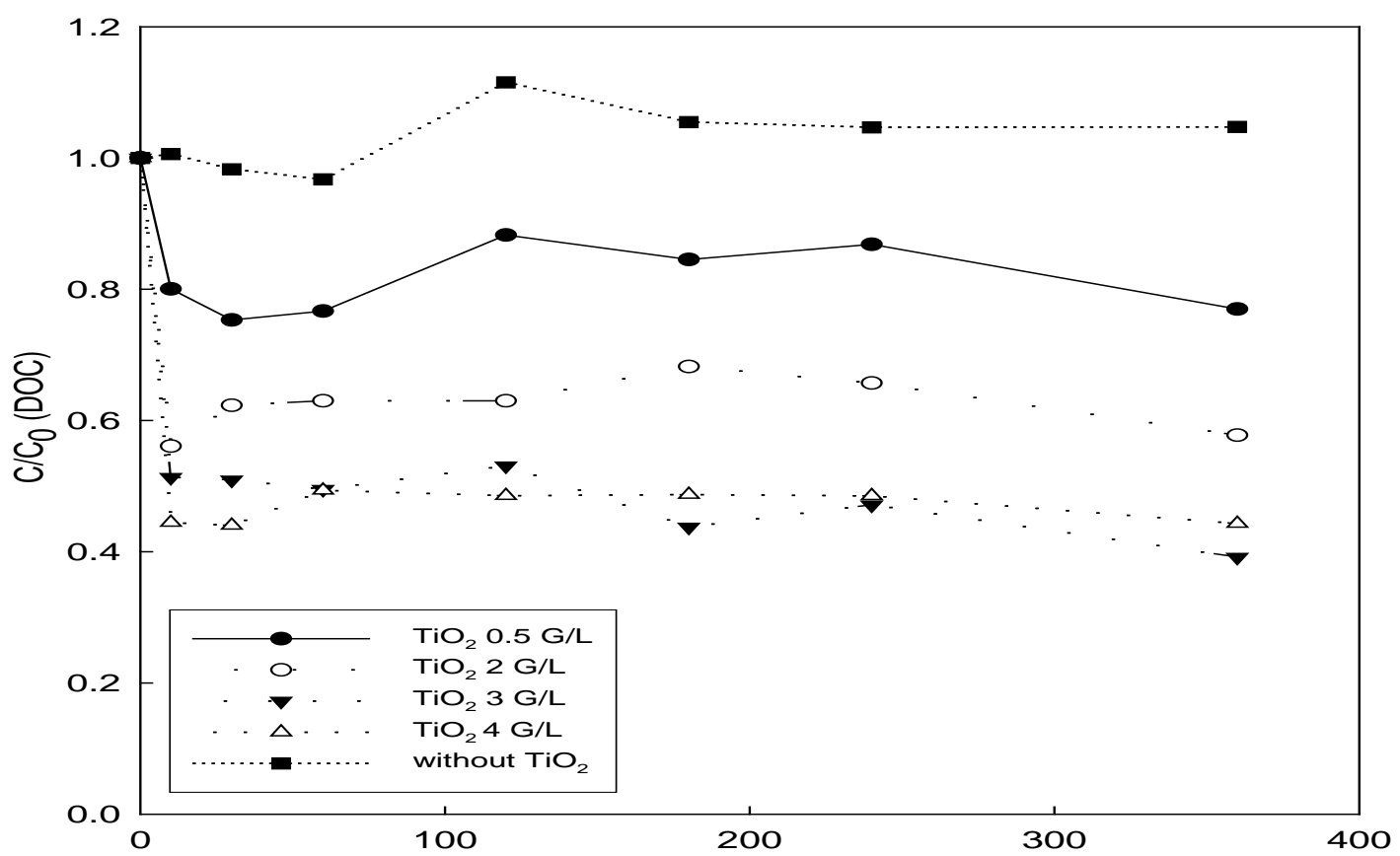

Figure 7 Removal of humic substances (DOC) with different concentration of $\mathrm{TiO}_{2}$ with UV treatment (including UV treatment without $\mathrm{TiO}_{2}$ ) in a batch reactor. (Influent TOC $=10 \mathrm{mg} / \mathrm{L}$ ) 


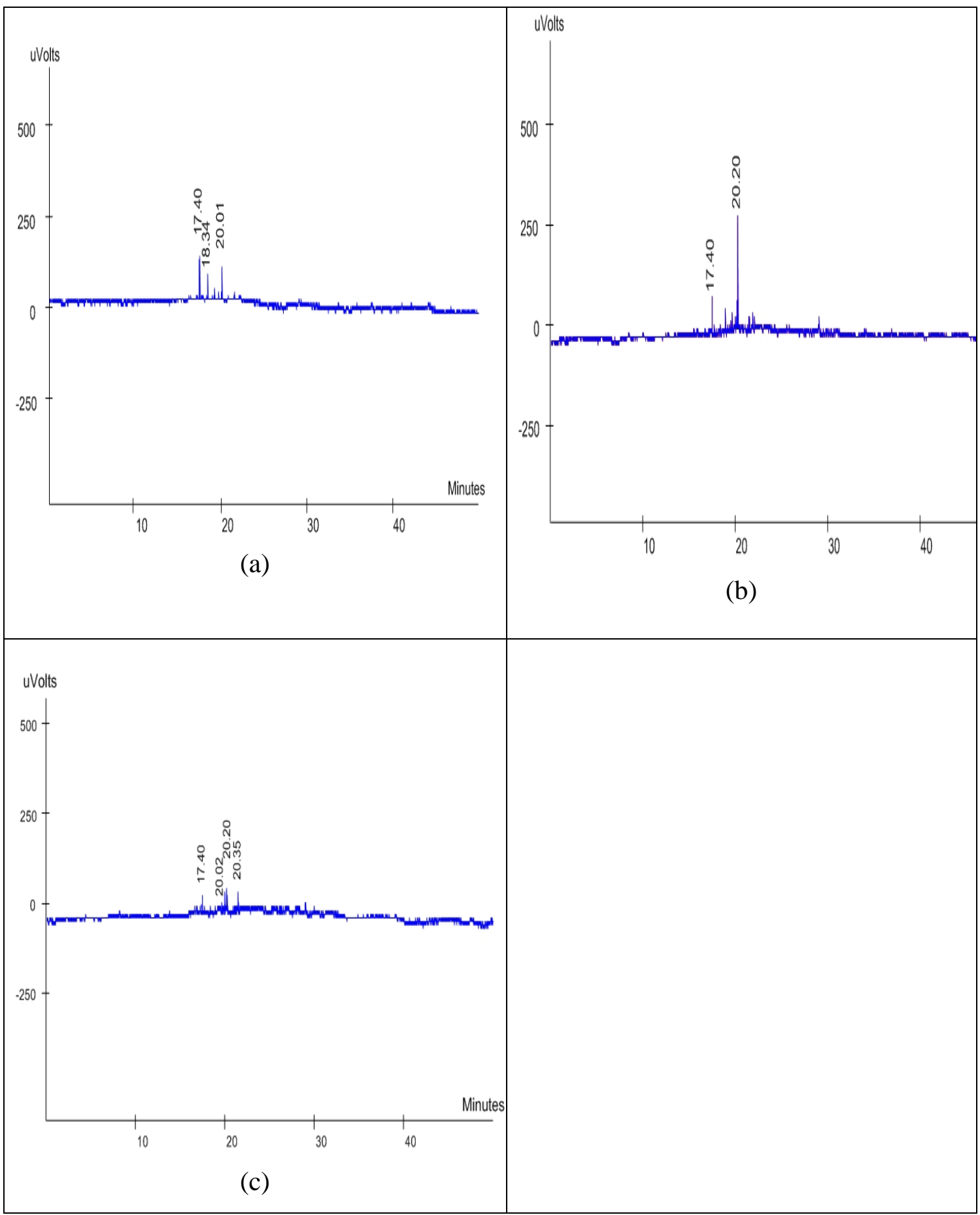

Figure 8 SPME/GC (a) at $15 \mathrm{~min}$ (b) at $90 \mathrm{~min}$ (c) at $240 \mathrm{~min}$. Humic substances $100 \mathrm{mg} / \mathrm{l}$ and $\mathrm{TiO}_{2} 2 \mathrm{~g} / \mathrm{l}$. 


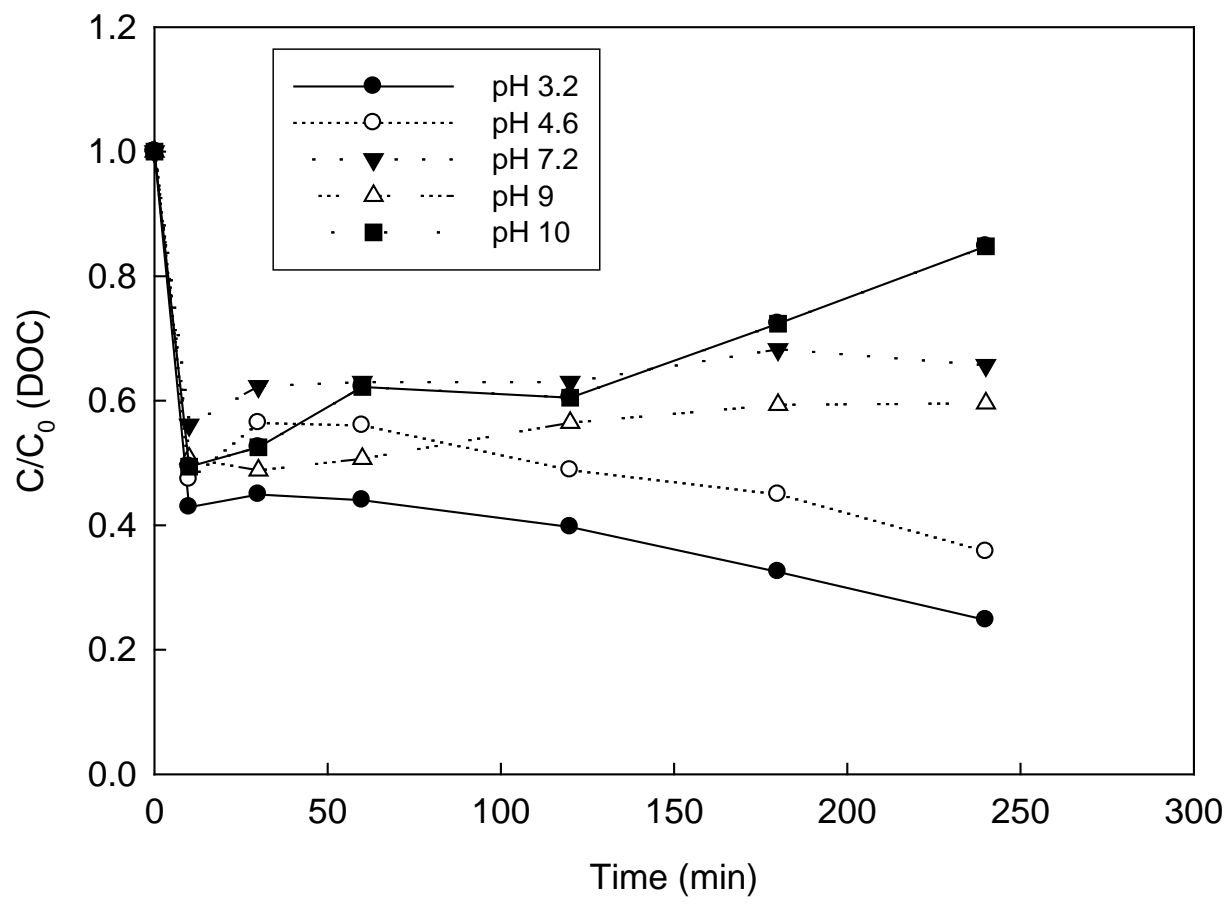

Figure 9 Removal of humic substances (DOC) with $2 \mathrm{~g} / \mathrm{L}$ of $\mathrm{TiO}_{2}$ at different initial levels of $\mathrm{pH}$ in batch reactor. (Influent TOC $=10 \mathrm{mg} / \mathrm{L}$ ) 


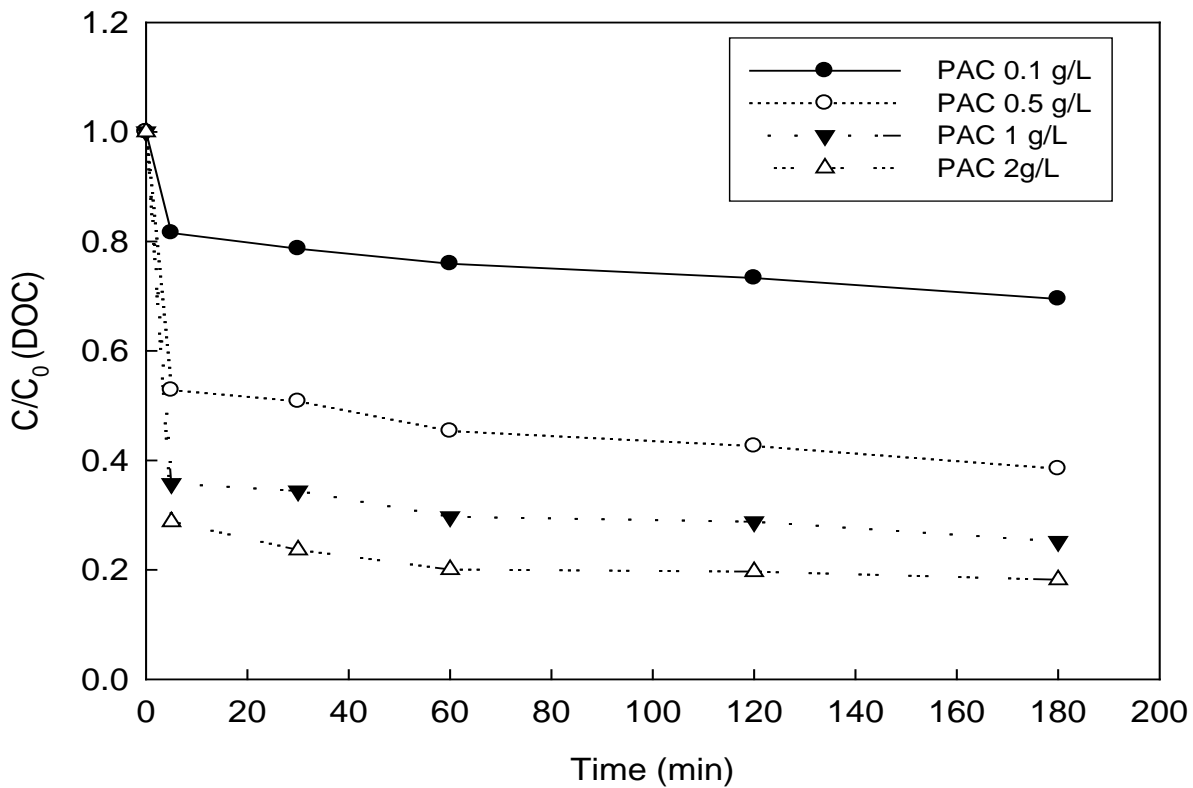

Figure 10 Removal of humic substances (DOC) at different concentrations of PAC. (Influent $\mathrm{TOC}=10 \mathrm{mg} / \mathrm{L})$ 


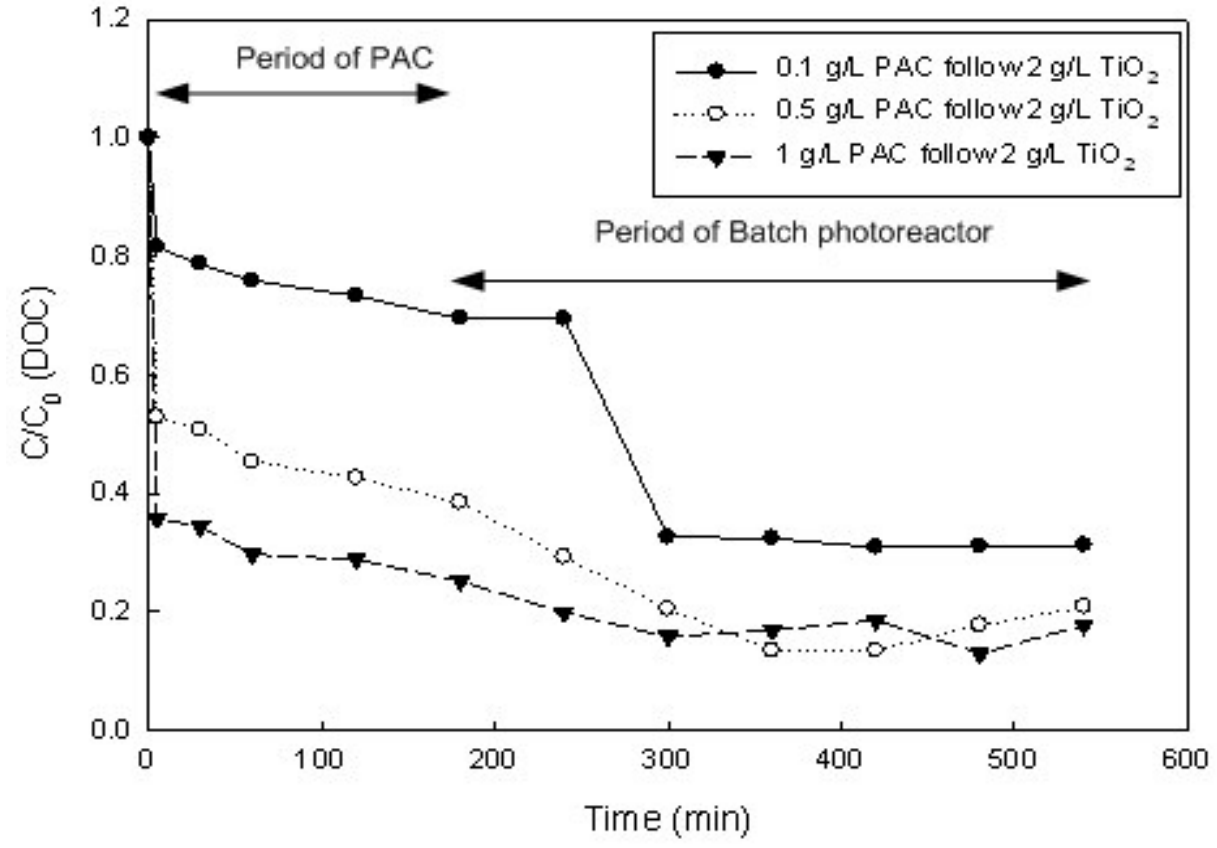

Figure 11 Removal of humic substances (DOC) using PAC as pre-treatment follow by batch photocatalytic reactor. (Influent TOC = $10 \mathrm{mg} / \mathrm{L}$ ) 


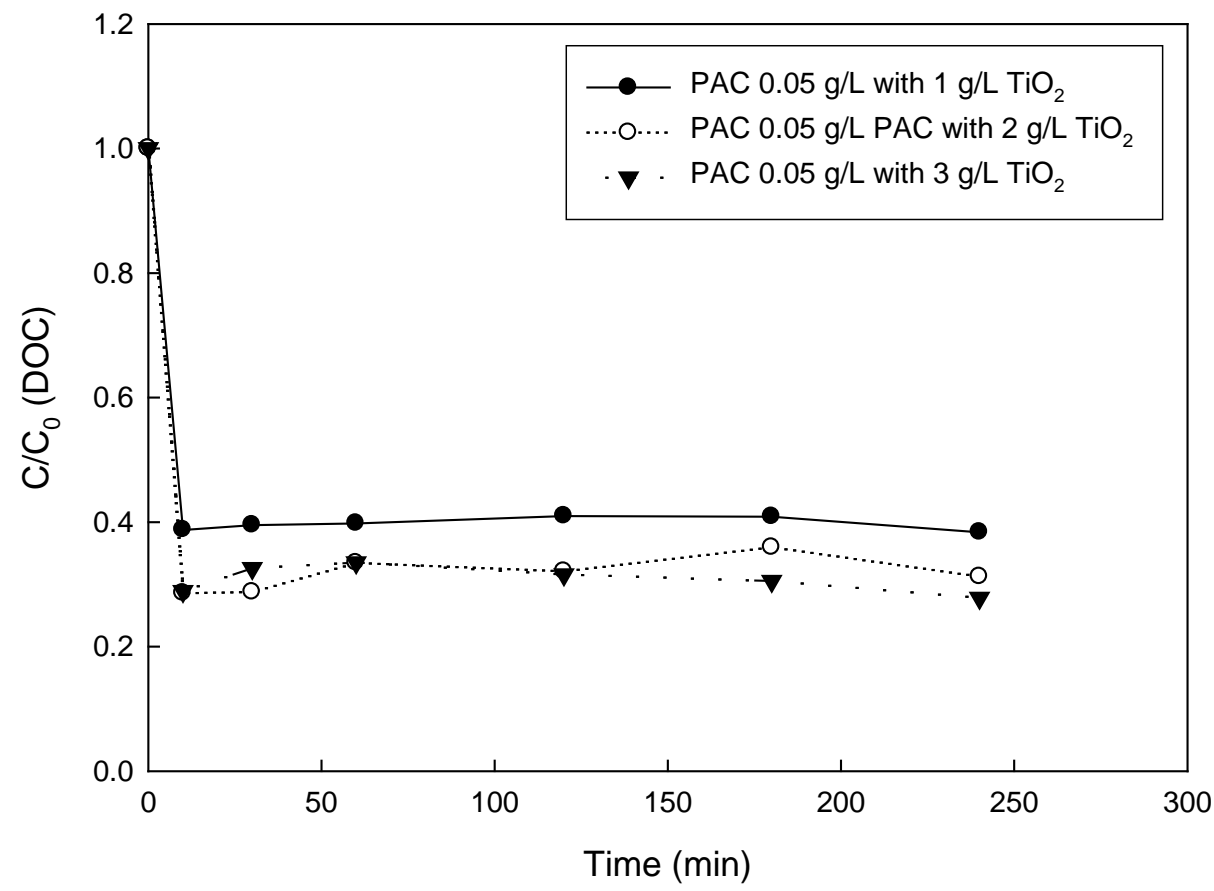

Figure 12 Removal of humic substances (DOC) with $0.05 \mathrm{~g} / \mathrm{L}$ PAC and different concentration of $\mathrm{TiO}_{2}$. (Influent TOC $=10 \mathrm{mg} / \mathrm{L}$ ) 


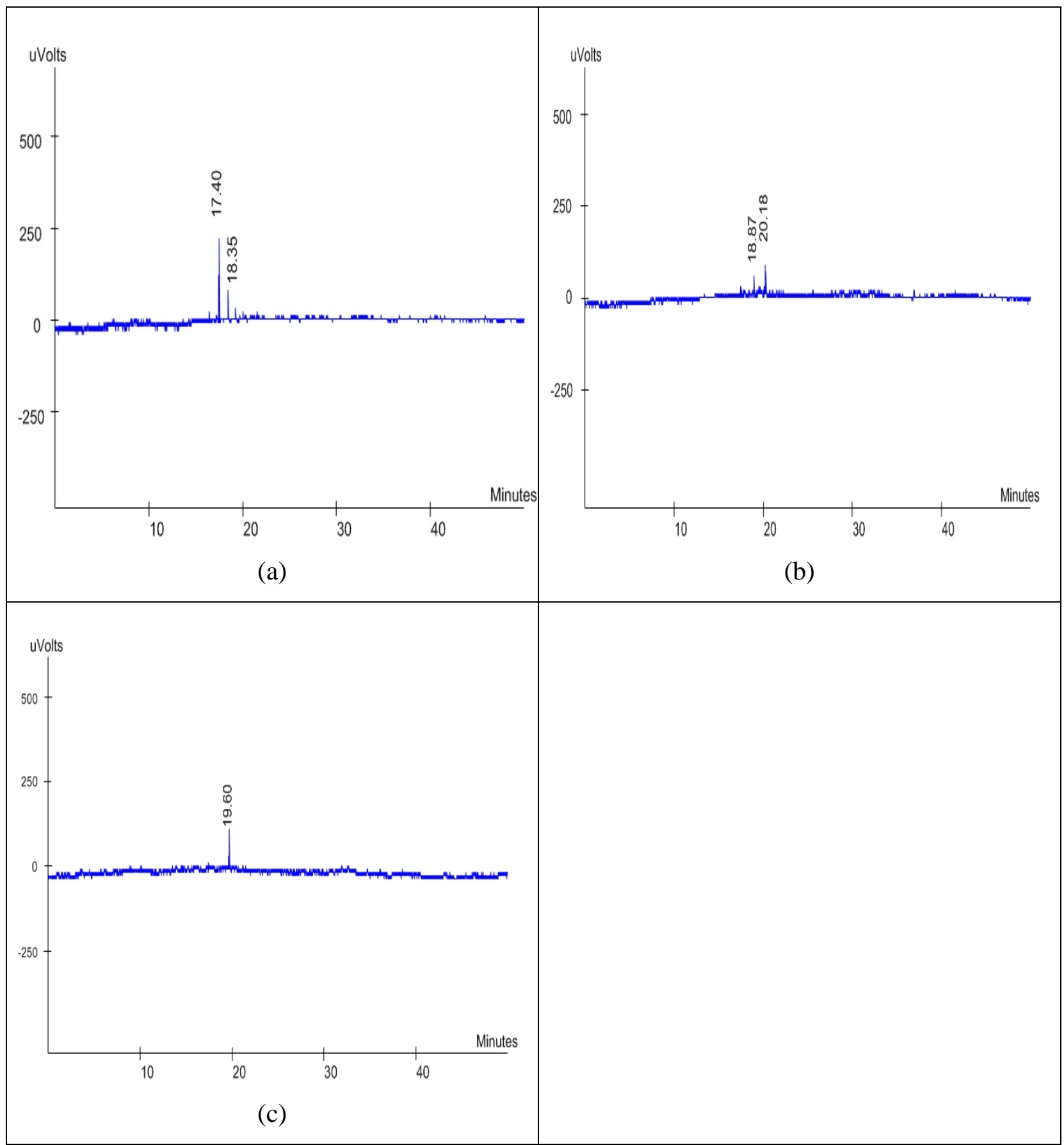

Figure $13 \mathrm{SPME} / \mathrm{GC}$ peaks $\mathrm{PAC}-\mathrm{TiO}_{2}$ (a) at $15 \mathrm{~min}$ (b) at $90 \mathrm{~min}$ (c) at $210 \mathrm{~min}$. humic substances $100 \mathrm{mg} / \mathrm{L}, \mathrm{TiO}_{2} 2 \mathrm{~g} / \mathrm{L}, \mathrm{PAC} 0.05 \mathrm{~g} / \mathrm{L}$ 


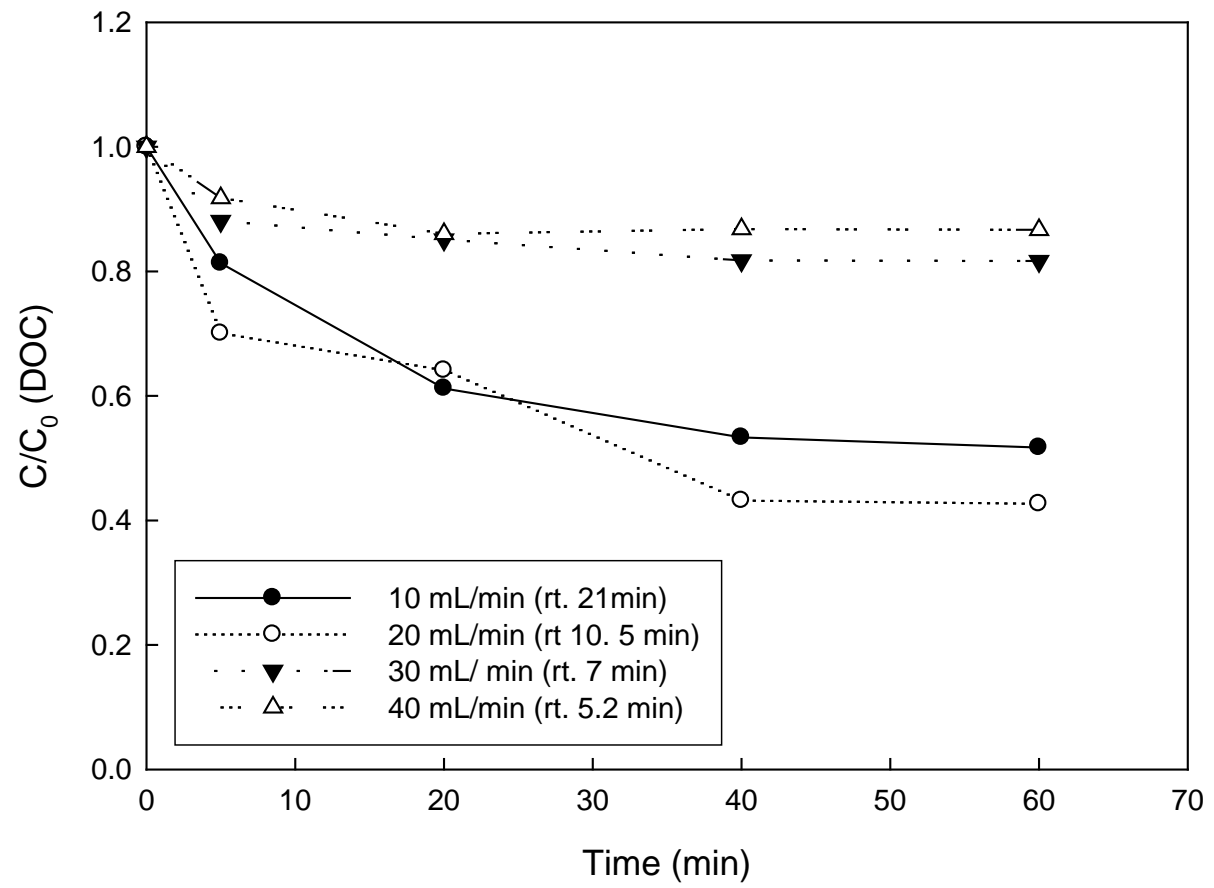

Figure 14 Removal of humic substances (DOC) with $2 \mathrm{~g} / \mathrm{L}$ of $\mathrm{TiO}_{2}$ by continuous reactor in various flow rates. (Influent TOC $=10 \mathrm{mg} / \mathrm{L}$ ) 


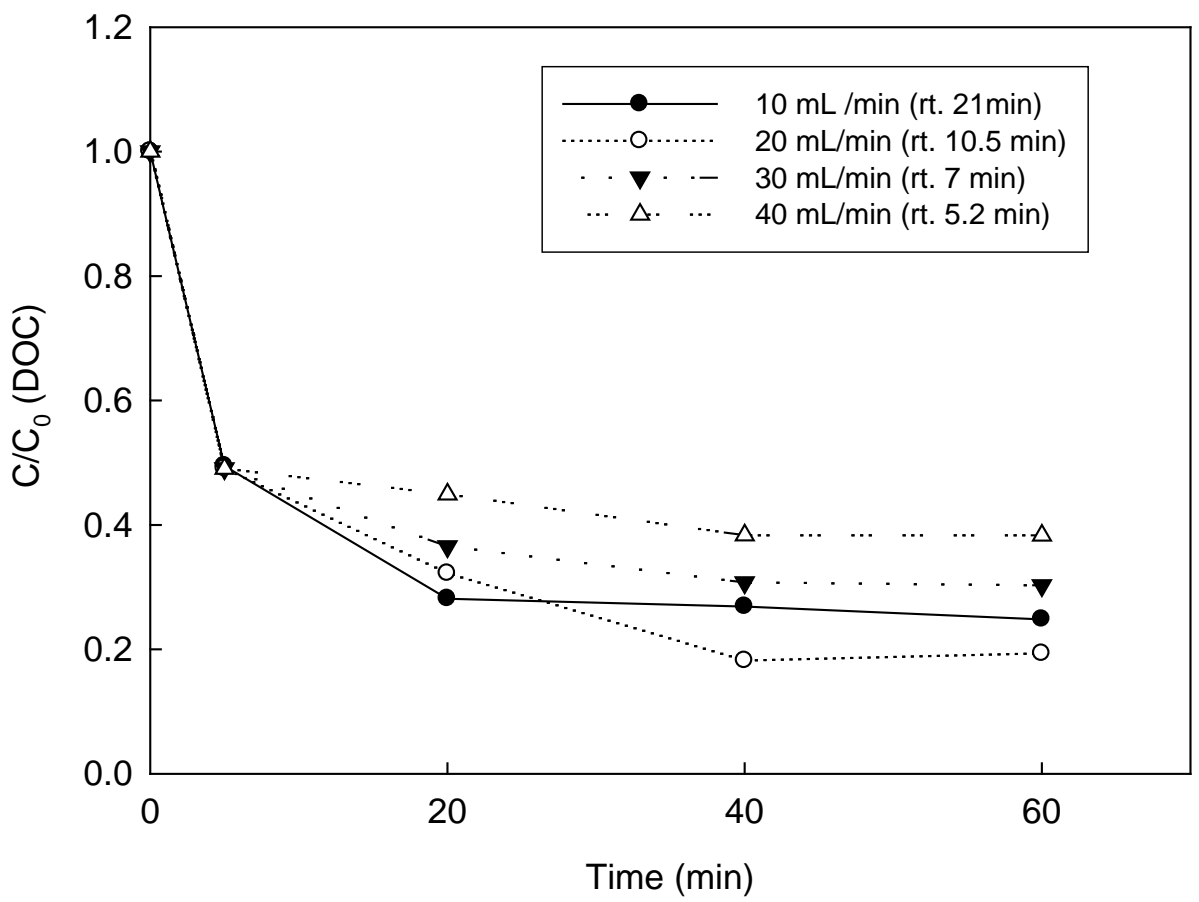

Figure 15 Removal of humic substances (DOC) with $2 \mathrm{~g} / \mathrm{L}$ of $\mathrm{TiO}_{2}$ and $0.05 \mathrm{~g} / \mathrm{L}$ of PAC by continuous reactor in various flow rates. (Influent TOC = $10 \mathrm{mg} / \mathrm{L}$ ) 


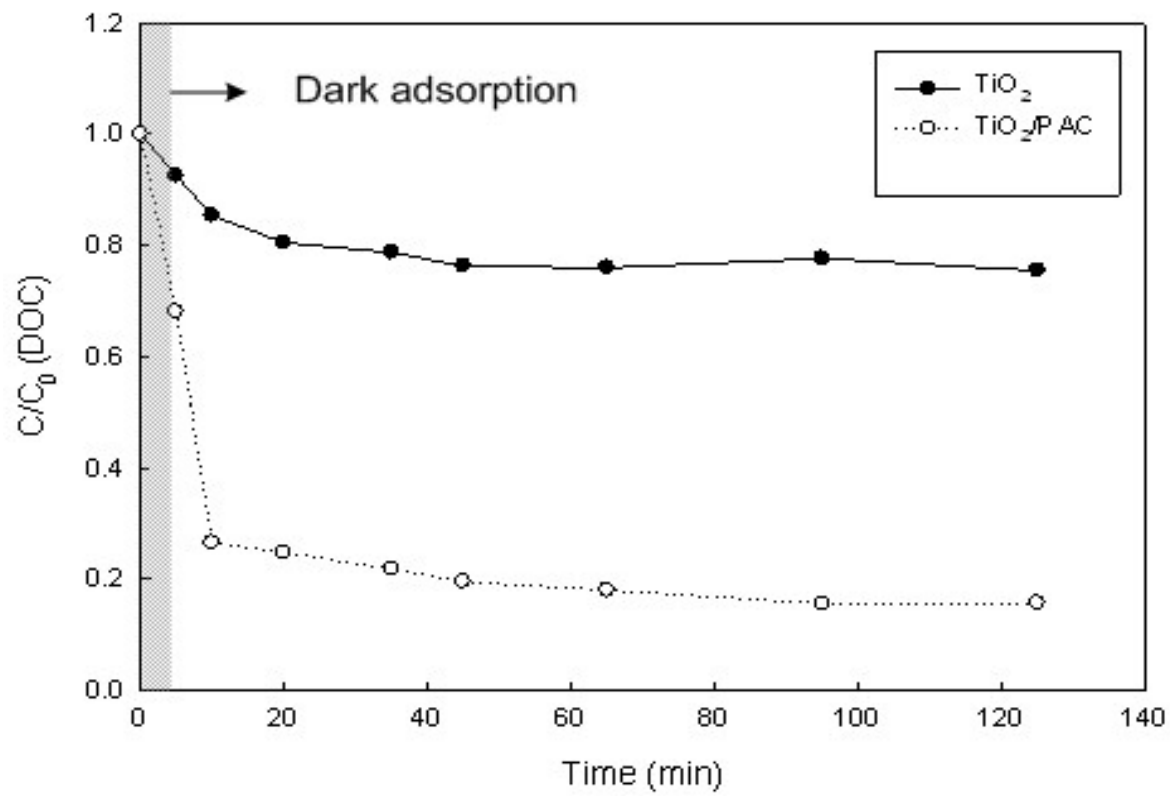

Figure 16 Removal of humic substances (DOC) in recirculated continuous flow reactor at withdrawal rate of $20 \mathrm{~mL} / \mathrm{min}$. (Influent TOC $=10 \mathrm{mg} / \mathrm{L}, 0.5 \mathrm{~g} / \mathrm{L}$ of $\mathrm{TiO}_{2}$ and $0.05 \mathrm{~g} / \mathrm{L}$ of PAC) 


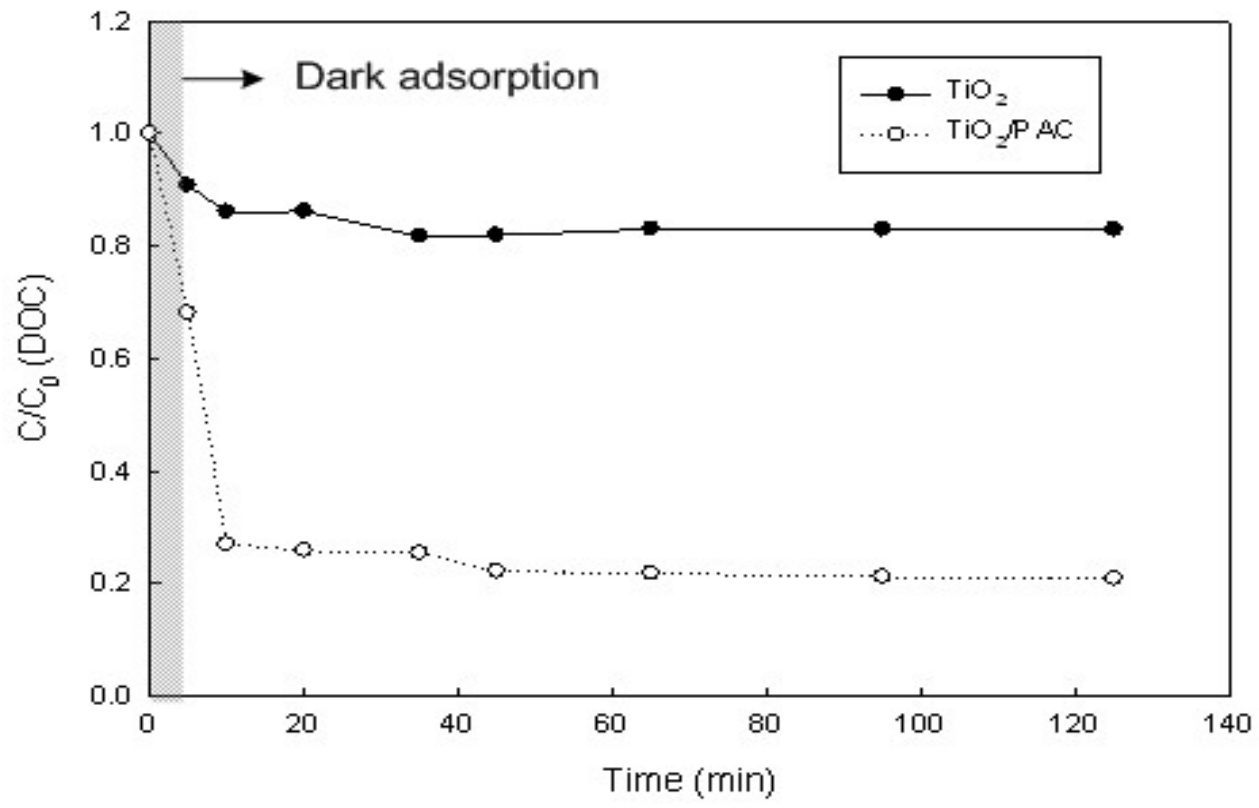

Figure 17 Removal of humic substances (DOC) in recirculated continuous flow reactor at withdrawal rate of $40 \mathrm{~mL} / \mathrm{min}$. (Influent TOC $=10 \mathrm{mg} / \mathrm{L}, 0.5 \mathrm{~g} / \mathrm{L}$ of $\mathrm{TiO}_{2}$ and $0.05 \mathrm{~g} / \mathrm{L}$ of PAC) 